\title{
Study on the Development Strategies of Changchun Movie Wonderland Based on Tourist Experience
}

\author{
Chunyan Wang \\ College of Business Administration, Jilin Engineering Normal University, Changchun, China
}

541012329@qq.com

Keywords: Changchun Movie Wonderland; Tourist experience; Development; Strategy

\begin{abstract}
The quality of tourist experience is an important indicator to measure the satisfaction of tourists, and it is also the embodiment of the sustainable and stable development of theme parks. In this paper, Changchun Movie Wonderland as the research object, based on tourist experience theory and customer satisfaction theory, it analyzes some samples such as questionnaires, tourist's blogs and interviews with tourists and scenic staff. By using statistical analysis, it argues that some main factors, including entrance fee, tourist participation and travel time and so on, affect the tourist experience in Changchun Movie Wonderland. Finally, this paper puts forward some strategies on the development of Changchun Movie Wonderland from the view of tourist experience.
\end{abstract}

\section{Introduction}

Changchun Movie Wonderland is located in Changchun Jingyue Tour Economic Development district, is a 5A-class tourist attraction and China's first movie theme park which are combined with film industry and tourism, to fill the gaps in the Chinese industry tourism about movie. Changchun Movie Wonderland is the first world-class movie theme park, known as "China Disneyland". In the setting of project, there are four sections--scientific and technological innovation, thrilling stimulation, acting experience and entertainment. They show representative technology of special-effects film in today's world, such as 4D film, laser film, giant screen film and water curtain film and so on [1].

Since its opening in May 2005, the popularity of Changchun Movie Wonderland expanded and its number of visiting tourists was increasing year by year, its development trend is rapid. During holiday of "National Day" in 2015, the number of tourists in Changchun Movie Wonderland up to 43.6 thousand person-time, its earning from tickets reached 8 million yuan, an increase of 9.94\% [2]. The economic effect of Changchun Movie Wonderland was far more than other traditional tourist attractions in Jilin Province. Under the effect of tourism multiplier, the economic benefits created by Changchun Movie Wonderland are greater than that of its ticket revenue. In the process of traveling, the tourist consumption including catering, accommodation, shopping and so on has made an important contribution to the economic growth of the local tourism. However the theoretical research about Changchun Movie Wonderland is relatively weak. The past research about Changchun Movie Wonderland Century City mainly focused on the perspective of marketing, project management and leadership training. The research results about tourist experience and tourists satisfaction of Changchun Movie Wonderland Century City are less than others.

\section{Research Methods and Research Analysis}

Research Methods. Changchun Movie Wonderland as the research object, the tourist experience perception is the main measure to evaluate tourist satisfaction through questionnaire survey. In view of the survey length are limited, this study combined with the analysis of tourist blogs and interviews with scenic staff. In this paper, the research analysis is mainly based on the questionnaire survey, and is supplemented by the tourist blogs and the interviews with scenic staff. The study used quantitative analysis methods to analyze the questionnaire survey and to explain the tourist blogs and interviews by using the qualitative analysis methods. 
Research Analysis. From August 28 to August 30 in 2015, the research team made a questionnaire survey of Changchun Movie Wonderland for a period of 3 days. The object of this investigation is the tourist who first time visit or ever visit Changchun Movie Wonderland. The survey sites selected the exit areas of Changchun Movie Wonderland. A total of 300 questionnaires were distributed, 257 were recovered, the recovery rate was $85.7 \%$, and the effective questionnaires were 236, and the effective rate was $91.8 \%$. In this paper, it uses SPSS to analyze these data, and then draw the conclusion. The analysis methods include mean value analysis, frequency analysis, factor analysis and satisfaction analysis etc.. The average reliability coefficient (a) of the questionnaire was 0.799 , so the reliability of the questionnaire was high. The basic information of survey sample is shown in Table 1.

Table 1 The basic information of survey sample

\begin{tabular}{|c|c|c|c|c|}
\hline Measuring items & Classification & $\begin{array}{c}\text { Frequency } \\
\text { (Person) }\end{array}$ & $\begin{array}{c}\text { Proportion } \\
(\%)\end{array}$ & $\begin{array}{c}\text { Cumulative } \\
\text { Frequency }(\%)\end{array}$ \\
\hline \multirow{2}{*}{ Sex } & Male & 109 & 46.2 & 46.2 \\
\hline & Female & 127 & 53.8 & 100 \\
\hline \multirow{4}{*}{ Age } & $<14$ & 12 & 5.1 & 5.1 \\
\hline & $\geq 14,<25$ & 107 & 45.3 & 50.4 \\
\hline & $\geq 25,<45$ & 108 & 45.8 & 96.2 \\
\hline & $\geq 45$ & 9 & 3.8 & 100 \\
\hline \multirow{3}{*}{ Educational level } & Junior high school and below & 10 & 4.2 & 4.2 \\
\hline & High school or vocational school & 94 & 39.8 & 44 \\
\hline & Bachelor's degree or above & 132 & 56 & 100 \\
\hline \multirow{3}{*}{ Place of residence } & Changchun city or Jilin province & 109 & 46.2 & 46.2 \\
\hline & Three province in Northeast China & 86 & 36.4 & 82.6 \\
\hline & Other areas & 41 & 17.4 & 100 \\
\hline \multirow{2}{*}{ Marital status } & single & 167 & 70.8 & 70.8 \\
\hline & married & 69 & 29.2 & 100 \\
\hline \multirow{4}{*}{$\begin{array}{l}\text { The frequency of } \\
\text { visiting }\end{array}$} & 0 time & 54 & 22.9 & 22.9 \\
\hline & 1-2 times & 165 & 69.9 & 92.8 \\
\hline & 3-4 times & 17 & 7.2 & 100 \\
\hline & above 4 times & 0 & 0 & 100 \\
\hline \multirow{4}{*}{$\begin{array}{l}\text { The number of } \\
\text { people who travel } \\
\text { together }\end{array}$} & Single one & 27 & 11.4 & 11.4 \\
\hline & 1-2 person & 95 & 40.3 & 51.7 \\
\hline & 3-4 persons & 90 & 38.1 & 89.8 \\
\hline & 5 persons and above & 24 & $\frac{50.1}{10.2}$ & 100 \\
\hline
\end{tabular}

From Table 1, it can be known the basic individual information and travelling information about visitors who visit Changchun Movie Wonderland. In gender distribution, the proportion of male and female is essentially same, and the proportion of female is slightly more than male, accounting for $53.8 \%$; in the term of age, tourists mainly are in the 14 25 years old and 25 44 years old, respectively was $45.3 \%$ and $45.8 \%$, that is the main tourists of this movie theme park are young and middle-aged people; in the level of education, these tourists are mainly in undergraduate and above, accounting for $56 \%$ of the total number of visitors, that shows the tourists who visit Changchun Movie Wonderland have higher education; in the term of tourist market, the tourists are mainly from Changchun city or Jilin province and neighboring provinces, the proportion of $46.2 \%$ and $36.4 \%$ respectively. By the interviews with tourists, we know that the tourists mainly from the surrounding provinces, such as Heilongjiang province and Liaoning Province, so the marketer need to focus on marketing in the surrounding market; in marital status, unmarried person are the majority, this situation matches the market survey that tourists of Changchun Movie Wonderland are mainly concentrated in the middle-aged and young; in the visiting times, most tourists visit 0 times or 1 2 times, accounting for $22.9 \%$ and $69.9 \%$ respectively; and the number of people in this tour, most of 
tourists are accompanied with friends, classmates or relatives, commonly $2 \sim 4$ person in one group, they often select some strong interactive projects; in the number of visiting days, most of tourists choose one-day trip, its main reason is that the number of projects in Changchun Movie Wonderland is less and limit; in the cognition source of Changchun Movie Wonderland, the main cognitive ways of Changchun Movie Wonderland are introduction from media or friend's recommendation.

Table 2 The survey of tourists' motivation

\begin{tabular}{|l|c|c|}
\hline Tourist motivation & Mean & Sorting \\
\hline To experience the advanced technology of theme park & 3.72 & 2 \\
\hline To look for some familiar scenes in the film or TV drama & 2.13 & 6 \\
\hline Be attracted to a place by its reputation as a scenic spot & 3.64 & 3 \\
\hline To get rid of busy work temporarily & 3.85 & 1 \\
\hline To pursue a new travel experience & 3.46 & 4 \\
\hline For accompanying some friends & 2.8 & 5 \\
\hline
\end{tabular}

From Table 2, we can know that the first tourist's motivation is temporarily out of the busy work, so Changchun Movie Wonderland should pay more attention to the function of entertainment in the project settings. To experience the advanced technology of the theme park came in second place, that because Changchun Movie Wonderland mainly displays the advanced movie technology; the third one is admiring that tourists visit Changchun Movie Wonderland for his curious and conformity psychological need. Therefore, in the management of the theme park should pay attention to guide, to improve the satisfaction of tourists, and enhance the sustainable development of movie theme park.

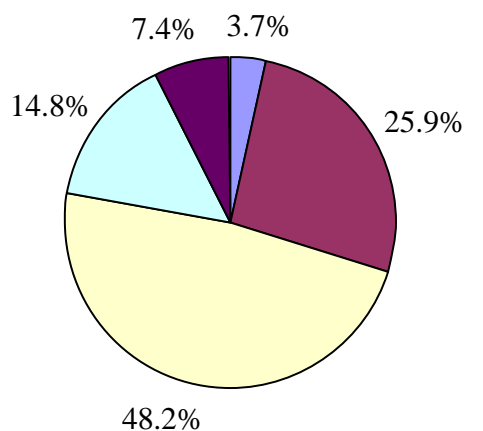

$$
\begin{aligned}
& \square \text { Very satisfied } \\
& \square \text { Satisfied } \\
& \square \text { Neither satisfied nor dissatisfied } \\
& \square \text { Dissatisfied } \\
& \square \text { very dissatisfied }
\end{aligned}
$$

Figure 1. The statistical analysis of overall satisfaction in Changchun Movie Wonderland

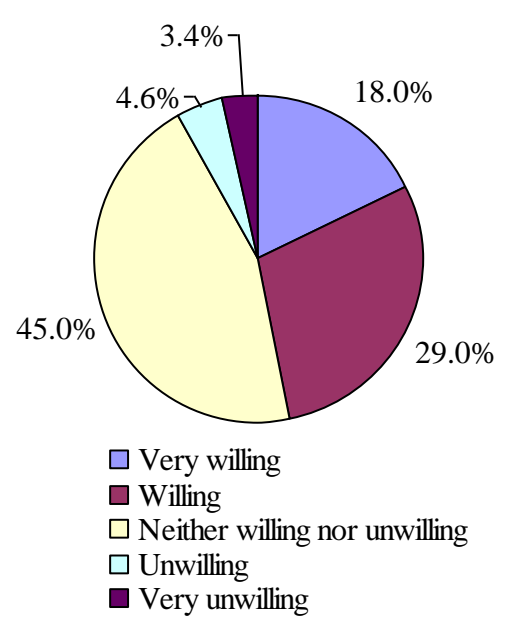

Figure 2. The statistical analysis of revisiting Changchun Movie Wonderland

As is shown in Fig. 1, in the term of overall tourist satisfaction in Changchun Movie Wonderland, the majority evaluate "satisfied" or "neither satisfied nor dissatisfied", that means the overall experience of tourists basically satisfied. From Fig. 2 shows, in the selection of "revisit Changchun Movie Wonderland", the largest proportion of tourists is "neither willing nor unwilling", the proportion reached $45.0 \%$, which in a certain extent that the long-term development ability of this theme park is weak. If it wants to achieve sustained and stable development, it must improve visitor's experience for increasing rate of revisiting. In the question of "whether or not to recommend Changchun Movie Wonderland to relatives and friends", the ratio of "willing" is 51.9\% (shown in Fig. 3). This result is consistent with the way of getting information about Changchun Movie Wonderland. In the improvement suggestions on the development of Changchun Movie Wonderland, the selection of ticket price is higher than others (shown in Fig. 4), which is also the status quo of most China's 
movie theme park currently, resulting in setting some barriers to entry the theme park. This research result is consistent with the tourist source age and educational level.

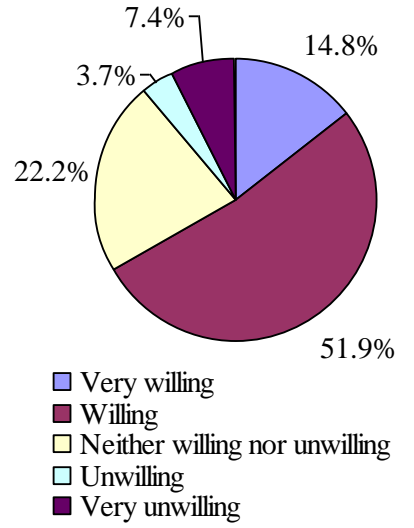

Figure 3. The statistical analysis of tourists' recommendation

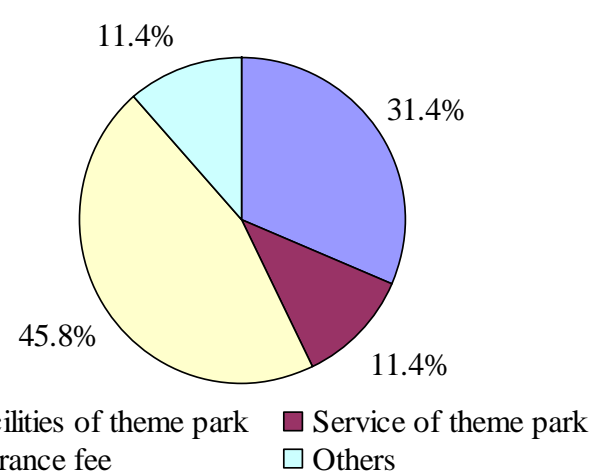

Figure 4. The statistical analysis of improvement

In the part of open-ended question, visitors reflect that the play time is limit and the project settings are lack of innovation. Their improvement suggestion is that the entertainment project should be combined with the current film and increase the cultural connotation and so on.

\section{Development Strategies of Changchun Movie Wonderland}

To Develop and Update Experience Products. Since Changchun Movie Wonderland Century City opened, there are 16 entertainment projects [3]. It adds 6 new projects until 2016. Its number of entertainment project is few, and the update degree is so slow, that has effect the revisit rate of tourists. In contrast, Disneyland, its business philosophy is "build a never-ending Disneyland", it adopts the triangular product life cycle strategy, that in every year it will update $1 / 3$ of the project, eliminate $1 / 3$ of the project, and build $1 / 3$ new projects [4]. As an entertainment theme park, do, it can always attract the attention of tourists. In the era of experience economy, just like Disneyland, the film and television tourism should develop new products and new projects on the basis of tourist experience. Make full use of all existing resources to improve the participation of tourists, so that visitors experience will be improved.

To Improve the Service Quality. The most of experience projects designed by the movie theme park should be achieved by employees and visitors, so the quality of service for tourists will effect on the tourist experience and satisfaction. The language, attitudes, behaviors and skills of employees directly affects the interaction effects, and the quality of interactive effects will directly affect the tourists' satisfaction. The staff should provide personalized service or higher quality service according to the different types of tourists in the aspects of time and space [5]. Based on the tourist blogs, in Changchun Movie Wonderland the price of tour guide service and shuttle service are higher. The tourists believe that the cost performance of these service are low, and reduce the overall service experience. In addition, tourism information center and public service platform should be set up to strengthen the management of tourism service, and to improve the quality of service.

To Price the Tickets from the Perspective of Tourist Experience. The movie theme park in the pricing must consider how to reduce the cost of tourists, how to make full use of their own advantages to improve tourist's experience, to create the perfect tourist experience [6]. In the specific price strategy, low ticket and multi-services strategy is future trend of pricing in theme park, namely low ticket to attract visitors, increase profits by extending the industrial chain of movie [7]. For example, to improve profits of movie theme park through the extension of the tourist retention time, providing special catering, sales of tourism souvenirs and the development of film tourism products, etc. In brief, the ticket prices of Changchun Movie Wonderland should match with the tourist practical experience, so that visitors feel "value for money", so as to enhance the value of experience. 
To Excavate the Cultural Connotation of Scenic Spots. Cultural connotation is the basis for the development of tourist attractions. High-level tourists market is mainly cultural and cognitive tourists, so scenic spots in the competition must pay more attention to expressing the cultural connotation [8]. The Changchun Movie Wonderland belongs to the Changchun Film Studio Group, it should rely on the culture of Changchun Film Studio Group. In the setting project, the park atmosphere should be embodied the culture of Changchun Film Studio Group and reflect the local culture, so that the soul of the culture can go into every nook and corner of the theme park, and the unique culture brand image of Changchun Movie Wonderland will be formed.

To Carry out Experiential Marketing. The experience value of tourism service, tourism facilities and tourist attraction is an important indicator of impacting on the overall tourists experience value [9]. Experience marketing can be carried out in the following aspects: Firstly, service marketing. The movie theme park should provide personality services and create emotional experience. The services in the movie theme park are provided by its employees, so the value of the tourists experience depends on staff services largely. Secondly, product marketing and product innovation. In the era of experience economy, tourists are pursuing a new, strange and different experience [10], so the movie theme park must keep the continuous development of new products to improve its sustainable and stable development ability. Thirdly, technology marketing. Changchun Movie Wonderland should use the advanced technology to rich the tourist experience and make full use of the latest technology to make experience marketing.

\section{Conclusion}

This paper analyzes the development of Changchun Movie Wonderland through questionnaire survey and interviews. From the view of tourist experience, it proposes the development strategies of Changchun Movie Wonderland from some aspects of product, service, pricing etc.. Since the research is made on season of Changchun Movie Wonderland, so this research has some limitations. In the future, the research could be made in different seasons, times and places. These researches may give some guidance and inspirations for the development of Changchun Movie Wonderland.

\section{Acknowledgements}

This work was financially supported by Social Science Foundation of Jilin Provincial Education Department ([2014] No.427) and the Research and Development Project of Jilin Engineering Normal University (X2015039).

\section{References}

[1] Information on http://www.cfs-cn.com/cyyw/cyfb/2015-08-31/41.html

[2] Information on http://www.ccta.gov.cn/zwgk/xwzx/20151013/1700.html

[3] Information on http://changying.com/

[4] W.Z. Wu and X.G. Feng: East China Economic Management, Vol. 27 (2013) No.2, p.142-148.

[5] H. Wang: Study on the Relationship between Theme Park Service Quality and Tourist Loyalty--A Case Study of Happy Valley in Shenzhen, (MS., Jinan University, China 2013), p.61.

[6] W.L. Zheng: Prices Monthly, Vol. 32 (2012) No.8, p.17-20.

[7] G.W. Wang and X.F. Li: Prices Monthly, Vol. 35 (2015) No.9, p.42-45.

[8] Q.Y. Yu and Y.Z. Xu: Inquiry into Economic Issues, Vol. 33 (2012) No.6, p.40-46.

[9] Y.H. Xu, W.L. Li, C.H. Lin and X.Y. Lu: Journal of Shanxi Agricultural University (Social Science Edition), Vol. 14 (2015) No.12, p.1240-1244. 
[10] X.Q. Zhang: Journal of Commercial Economics, Vol. 32 (2013) No.11, p.45-46. 